TITLE:

\title{
The dynamics of gyrification in the human cerebral cortex during development
}

\section{AUTHOR(S):}

Yoshida, Ririko; Ishizu, Koichi; Yamada, Shigehito; Uwabe, Chigako; Okada, Tomohisa; Togashi, Kaori; Takakuwa, Tetsuya

\section{CITATION:}

Yoshida, Ririko ...[et al]. The dynamics of gyrification in the human cerebral cortex during development. Congenital Anomalies 2017, 57(1): $8-14$

\section{ISSUE DATE:}

2017-01

URL:

http://hdl.handle.net/2433/217755

\section{RIGHT:}

This is the accepted version of the following article: YYoshida, R., Ishizu, K., Yamada, S., Uwabe, C., Okada, T., Togashi, K., and Takakuwa, T. (2017) Dynamics of gyrification in the human cerebral cortex during development. Congenital Anomalies, 57: 8-14.], which has been published in final form at http://doi.org/10.1111/cga.12179. This article may be used for non-commercial purposes in accordance with Wiley Terms and Conditions for Self-Archiving.; The full-text file will be made open to the public on 4 JAN 2018 in accordance with publisher's 'Terms and Conditions for Self-

Archiving.:; This is not the published version. Please cite only the published version.; この論文は出版社版でありません 。引用の際には出版社版をご確認ご利用ください。 


\section{Original article}

The dynamics of gyrification in the human cerebral cortex during development

\section{Short title: Fetal brain gyrification}

Ririko Yoshida ${ }^{1}$, Koichi Ishizu ${ }^{1}$, Shigehito Yamada ${ }^{1,2}$, Chigako Uwabe ${ }^{2}$, Tomohisa Okada ${ }^{3}$, Kaori Togashi $^{3}$, Tetsuya Takakuwa ${ }^{1}$

${ }^{1}$ Human Health Science, ${ }^{2}$ Congenital Anomaly Research Center, \& ${ }^{3}$ Diagnostic Imaging and Nuclear Medicine, Graduate School of Medicine, Kyoto University

Corresponding author: Dr. Tetsuya Takakuwa

Human Health Science, Graduate School of Medicine, Kyoto University

606-8507 Sakyo-ku Shogoin Kawahara-cyo 53, Kyoto, Japan

E-mail: tez@hs.med.kyoto-u.ac.jp

Tel/fax: +81-75-751-3931

\section{ABSTRACT}

This study quantitatively characterized cortical gyrus folding over human neocortical development by calculating the gyrification index (GI) in 22 human fetal specimens from 16 to 40 weeks with magnetic resonance imaging data. Gl values remained constant at approximately 1.0 until the fetal specimens reached $500 \mathrm{~g}$ body weight and $200 \mathrm{~mm}$ crown-ramp length $(\mathrm{CRL})$, respectively, and then increased in correlation with the body weight and CRL. The rostrocaudal GI distribution in the cerebral cortex revealed a correspondence of Gl peaks with indentations of early-generated primary sulci at 21 weeks of gestation and more frequently increased GI values in the parieto-occipital region than in the fronto-temporal region at 31 and 40 weeks of gestation. These results provide a quantitative reference set for gyrification in normal human cortical development, which may help reveal the mechanism of neurodevelopmental disorders.

Key Words: fetal cerebral hemisphere, gyrification index, magnetic resonance imaging, morphology, three-dimensional reconstruction

This article has been accepted for publication and undergone full peer review but has not been through the copyediting, typesetting, pagination and proofreading process which may lead to differences between this version and the Version of Record. Please cite this article as doi: $10.1111 /$ cga. 12179

This article is protected by copyright. All rights reserved. 


\section{INTRODUCTION}

During development, the human cortex changes from a smooth lissencephalic structure to a gyrencephalic structure. Sulci begin to appear on the surface of the cerebral hemisphere at approximately the middle of second trimester, and the characteristic interlocking $\mathrm{C}$ formation of the hippocampus and the dentate gyrus becomes noticeable when the crown-ramp length $(\mathrm{CRL})$ is approximately $150 \mathrm{~mm}$ (Chi et al. 1977a,b; Armstrong et al. 1995). The developmental pattern of the appearance of human sulci and gyri has been qualitatively studied (Connolly, 1940; Chi et al. 1977a,b; Dorovini-Zis \& Dolman, 1977); however, quantitative characterizations of gyrification are limited.

The gyrification index (GI) is a sensitive and easily accessible measure defining individual variation in cortical areas. This parameter permits the description of a mean value for the whole brain, but also enables local analysis of different brain regions. Recent studies have documented anomalies in global and local GI values in neurodevelopmental disorders such as autism, schizophrenia, and obsessive-compulsive disorder (Wobrock et al., 2010; Budday et al. 2014; Auzias et al. 2014). Quantitative characterizations of gyrification during development may help reveal the mechanism for such neurodevelopmental disorders. The present study attempted to provide a quantitative reference set for gyrification in normal human cortical development.

\section{MATERIALS AND METHODS}

\section{Human fetal specimens}

The ethics committee of the Kyoto University Graduate School and Faculty of Medicine approved this study (E986). Twenty-two fetuses (10 males and 12 females) from 16 to 40 weeks of gestation defined from the last maternal menstrual period that were diagnosed as externally normal were analyzed in the present study. Specimens were stored at the Congenital Anomaly Research Center of Kyoto University (Nishimura et al. 1968; Shiota 1991; Yamada et al. 2004). In most cases, pregnancy was terminated for socioeconomic reasons, under the Maternity Protection Law of Japan (Table 1). The upper limit of the fetal 
age allowed the artificial interruption of pregnancy has been changed from 28 weeks gestation to 22 weeks, which is based on the Notification from Ministry of Health, Labor and Welfare, during collection of samples. Well-preserved human embryos, diagnosed as externally normal were subjected to the MRI acquisition. Samples with apparent deformity and brain shrinkage were excluded from the analysis because prolonged fixation is known to cause Magnetic resonance imaging (MRI) artifacts and tissue shrinkage due to dehydration (van Duijn et al. 2011). Body weights and biparietal diameter (BPD) ranged from 80.6-3380.0 $\mathrm{g}$ and $31.1-99.3 \mathrm{~mm}$, respectively.

\section{MR image processing, 3D reconstruction and morphometry}

MRI data from fetuses were acquired from the Kyoto University Hospital (Kyoto, Japan) as DICOM formatted files. The conditions used for MRI data acquisition have been described elsewhere (Hamabe et al. 2013). All scan was conducted by using a 1.5T MRI system (EXCELART Vantage, powered by Atlas; Toshiba Medical Systems, Otawara, Japan) with knee or head coils. After getting localizers, T1-weighted and T2-weighted images were acquired. For T1-weighted images, a three-dimensional gradient-echo sequence was used with the following parameters: time-of-repetition (TR) / time-of-echo (TE), 30 / 7 milliseconds (ms); flip angle (FA), 50; field-of-view (FOV), $180 \times 135 \mathrm{~mm}$; matrix, $256 \times 192$; and slices, 70 - 150 of $0.7 \mathrm{~mm}$ thickness, resulting in isotropic $0.70 \mathrm{~mm}$ resolution. T2-weighted images were acquired using two-dimensional fast spin-echo sequence with the following parameters: TR / TE, 6000 / 108 ms; FOV, $180 \times 135$ mm; matrix, $256 \times 192$; and slices, 30 - 50 of 0.7 mm thickness, resulting in isotropic $2 \mathrm{~mm}$ resolution without inter-slice gap. MRI image processing of the embryonic Brain was performed as has been described elsewhere (Hirose et al. 2012). Resection of sequential two-dimensional (2D) images, 3D reconstruction, and CRL measurement was applied with the software OsiriX ${ }^{\mathrm{TM}}$ (version 3.9, Pixmeo SARL, Geneva, Switzerland). Sulci and gyri were identified by observation of both 3D reconstruction and serial coronal images.

This article is protected by copyright. All rights reserved. 


\section{Gyrification index (GI)}

The degree of cortical convolution was quantitatively evaluated by calculating the gyrification index (GI) of 2D MRI slices according to the procedure described by Zilles et al. (1988). The total length of the outer (pial) cortical contour and the length of superficially exposed parts of the outer contour (rather than those buried in the sulci) in serial MR imaging data, and then calculating the ratio between these measurements in the same imaging data (Figure 1). The merits of these modified methods are that the measurement, the gyrification index $(\mathrm{Gl})$, is not biased by shrinkage artifacts introduced by fixation and histological processing. Coronal MR image, vertical to the orbito-meatal base line (OM line) were used for analysis. The thickness per slice was $1 \mathrm{~mm}$. The total number of sections/brain sample was between 42 and 147 slices.

\section{RESULTS}

\section{The primary and secondary sulci formation}

The lateral fissure (Sylvian fissure), cingular sulcus, olfactory sulcus, calcarine fissure, and parieto-occipital fissure were visible in the specimens when fetal body weight (bw) reached $\geq 281 \mathrm{~g}$ (data not shown). In fetuses of around $500 \mathrm{~g} \mathrm{bw}$, rapid growth of the cortex was apparent, as was formation of the sulci, which was reflected in increases in Gl values (Figure 2). In addition, the insula becomes increasingly buried once this bw is achieved. In a $1409 \mathrm{~g}$ fetus, the primary sulci were clearly evident, including the circular insular sulci, superior frontal sulcus, intraparietal sulcus, precentral sulcus, postcentral sulcus, inferior frontal sulcus, and inferior temporal sulcus (Chi et al. 1977b)(Figure 3). The secondary sulci and tertiary sulci, which are the last to appear in development, were observed in a $3380 \mathrm{~g}$ fetus (Figure 4). 


\section{Body weight, CRL, and GI}

Gl values remained relatively constant at approximately 1.0 until body weight reached $500 \mathrm{~g}$, when the $\mathrm{CRL}$ was $200 \mathrm{~mm}$. At this point, the $\mathrm{Gl}$ and CRL began to increase (Figure 5), surpassing 2.0 and $353 \mathrm{~mm}$, respectively, in the $3000 \mathrm{~g}$ fetus.

We assessed the effects of cortical hemisphere on GI. While line graphs of the right and left $\mathrm{Gl}$ in the rostro-caudal dimension were not exactly similar, mean GI values did not differ significantly between right and left hemispheres (Table 1, Figure 5).

Gls of cerebral hemispheres of both sexes during fetal periods are shown in Figure 6 . The regression line appears different because of the small number of samples and the deviated distributions of age and sex.

\section{The rostro-caudal GI pattern and its relationship with cortical areas}

We found that the Gl of the whole hemisphere changed in the rostro-caudal dimension. Several maxima of the Gl curve appeared in relation to gross landmarks in the $281 \mathrm{~g}$ fetus. One maximum was within the prefrontal cortex (around section a in Figures 2, 3, and 4). Another maximum was present at the beginning of the temporal lobe (around section b), and still another maximum was present at the end of the temporal lobe (around section c). GI values remained high between the second and third maxima, at which the lateral fissure was located. These local maxima became inconspicuous in the 40 week old fetus (the $3340 \mathrm{~g}$ fetus), at which time cortical folding proceeded in all prefrontal regions, resulting in an average increase in the GI values. The highest Gl values were observed from the occipital to parietal regions (around section d). 


\section{DISCUSSION}

In this study, we quantitatively assessed the dynamics of brain gyrification in human fetal development. GI in the adult human brain has been reported in several studies and determined to be 2.56-3.1(Elias \& Schwartz 1969, Zilles et al. 1988). Measurement of GI values during human development has heretofore been limited to a single study (Armstrong et al. 1995), which found that GI shortly before birth was approximately $90-95 \%$ that of adults, which is consistent with our findings.

Armstrong et al. (1985) subdivided the brain into three regions along the rostral-caudal direction (frontal, middle, and caudal thirds) and compared their Gl values between 11 weeks of gestation and 32 weeks after birth. Distinct differences were found between the three regions in the onset, duration, and completion of Gl increases during development. The caudal third (parieto-occipital region) reached the adult degree of cortical folding earlier than the frontal or middle thirds. The frontal third (pre-frontal region) took the longest to reach a degree of cortical folding, comparable to that in adults, and showed GI values at birth considerably lower than those in adults. The sulcal maturation revealed by progression of the degree of cortical convolution first at the level of the central sulcus, second in the temporo-parietooccipital lobe, and third in the frontal lobe (Dubois et al. 2008). The present study confirmed and built on Armstrong et al.'s study, providing more precise characterizations of GI values in the rostral-caudal direction. This is the first study to show the developmental course of rostrocaudal Gl distribution throughout the cerebral cortex in 16 to 40 week old human fetuses, including the periods of sulcogyrogenesis. The GI value around the parieto-occipital region was comparable between the 40 week old fetus $(3380 \mathrm{~g})$ and adults, but approximately $30 \%$ lower than that in adults in the frontal two-thirds. This suggests that the $\mathrm{Gl}$ in the prefrontal and temporal regions continues to increase after birth.

This would be in keeping with several reports measuring GI in human and nonhuman primate brains. Zilles et al. (1998) quantified the Gl values of several prosimians and Old 
World monkeys, finding that the largest differences between human and nonhuman primate brains were in the prefrontal cortex and temporal lobe, in terms of both the pattern and the magnitude of gyrification differences. Specifically, Gl values in the prefrontal cortex were higher in humans than in other mammals. The GI values of each MRI slice were small throughout the cerebrum in the early stage (16 weeks of gestation), and their peaks corresponded to the indentations of early-generated primary sulci, such as the Sylvian fissure. The Gl values then increased in the caudal third (parieto-occipital) region in the middle and later stages (31 and 40 weeks of gestation). A similar ontogenetic pattern of Gl distribution during periods of primary sulcogyrogenesis has been observed in Old World cynomolgus monkeys (Sawada et al. 2010), and New World monkeys, common marmosets (Sawada et al. 2014). Sawada et al. (2012) also proposed developmental stages of the gyrification processes in primates based on cerebral growth and cortical folding. The periods of sulcogyrogenesis corresponded to Gyrification Stages 1 and 2, suggesting that the developmental processes of cortical folding are phylogenetically homologous among primate species, including humans. Conversely, the adult pattern of rostrocaudal Gl distribution in humans was strikingly different from that in the Old World monkey and New World msonkey groups, with increased Gl values in the frontal two-thirds (Zilles et al. 1988). This suggests that the interspecies differences in the gyrification pattern are the result of the progression of cortical infolding of the frontal two-thirds in humans after the completion of sulcogyrogenesis (Gyrification Stages 3 and 4).

The human prefrontal cortex and many temporal areas mediate evolutionarily advanced functions such as working memory, temporal integration, motivation, decision-making, self-awareness, creativity, language, and social interaction (Fuster 2002). A recent study showed that the prefrontal white matter volume increases during infancy in humans and chimpanzees (Sakai et al. 2011). The present study indicated that not only volume, but also cortical folding, as shown by an increased GI, may increase substantially after birth.

Several hypotheses have been proposed for the mechanism of gyrification. Sawada et al. 
(2014) used coronal MR images to measure changes in the cortical wall thickness in presumptive calcarine sulcal and non-sulcal regions of the occipital cortex of common marmosets. While the thickness of the cortical wall in both regions progressively increased, the cortical wall was approximately twice as thick in the non-sulcal region compared to the presumptive sulcal region. Their results support the hypothesis that regional differences in cortical growth are under genetic control (gyrogenetic theory) (Welker et al. 1990). In the present study, we could observe the cortical layer, but quantitative analysis was limited by the resolution of the MR images. It will be necessary to quantify the cortical thickness using MRI with much higher resolution than that in the present study. Recent studies show that genetic factors such as bRG in the outer subventricular zone may be involved in gyrification (Felz et al. 2010, Hansen et al. 2010).

The present study estimated GI using 2D coronal MR images, and thus GI value was measured precisely in the rostro-caudal direction, but not in other directions. Recent imaging techniques can estimate brain size and folding of the human cerebral cortex by local sphere region (Toro et al. 2008). Such local estimation will be useful for the further detection of local brain development and analysis of the relationship between local morphology and functional development. Additionally, our study provided a comprehensive characterization of $\mathrm{Gl}$ changes in cortical development that can be used as a valuable reference for research studies and clinical applications, in addition to providing insights into brain evolution and species differences. For instance, the timing of primary and secondary sulci formation has been considered to be an accurate marker of brain development in clinical radiological inspection of MRI slices (Garel et al. 2001). The Gl values provided here can thus be used as quantitative reference data describing normal brain development for clinical applications and research. Furthermore, they may contribute to revealing the mechanisms of neurodevelopmental disorders.

This article is protected by copyright. All rights reserved. 


\section{ACKNOWLEDGEMENTS}

This study was supported by Grants 25461642, 24119002, 26220004, 15H01119, 15K08134, $15 \mathrm{H} 05270,15 \mathrm{H} 01121$, and $15 \mathrm{~K} 15014$ from the Japan Society for the Promotion of Science.

\section{DISCLOSURES}

None

\section{REFERENCES}

Armstrong E, Schleicher A, Omran H, Curtis M, Zilles K. 1995. The ontogeny of human gyrification. Cereb Cortex 5:56-63.

Auzias G, Viellard M, Takerkart S, Villeneuve N, Poinso F, Fonséca DD, Girard N, Deruelle C. 2014. Atypical sulcal anatomy in young children with autism spectrum disorder. Neuroimage Clin 4: 593-603.

Budday S, Raybaud C, Kuhl, E. 2014. A mechanical model predicts morphological abnormalities in the developing human brain. Sci Rep 4:5644.

Chi JG, Dooling EC, Gilles, FH. 1977a. Left-right asymmetries of the temporal speech areas of the human fetus. Arch Neuro/ 34:346-348.

Chi JG, Dooling EC, Gilles FH. 1977b. Gyral development in the human brain. Ann Neurol $1: 86-93$

Connolly CJ. 1940. Development of the cerebral sulci. Am J Phys Anthropol 26:113-149.

Dorovini-Zis K, Dolman CL. 1977. Gestational development of brain. Arch Pathol Med 101:193-195.

Elias H, Schwartz D. 1969. Surface areas of the cerebral cortex of mammals determined by stereological methods. Science 166:1011-1013.

Fietz SA, Kelava I, Vogt J, Wilsch-Brauninger M, Stenzel D, Fish JL, Corbeil D, Riehn A, Distler W, Nitsch R, Huttner WB. 2010. OSVZ progenitors of human and ferret neocortex are epithelial-like and expand by integrin signaling. Nat Neurosci 13:690-699. 
Fuster JM. 2002. Frontal lobe and cognitive development. J Neurocyto/ 31:373-385.

Garel C, Chantrel E, Brisse H, Elmaleh M, Luton D, Oury J-F, Sebag G, Hassan M. 2001. Fetal cerebral cortex: normal gestational landmarks identified using prenatal MR imaging. $A m$ J Neuroradiol 22:184-189.

Hamabe Y, Hirose A, Yamada S, Uwabe C, Okada T, Togashi K, Kose K, Takakuwa T. 2013. Morphology and morphometry of fetal liver at 16-26 weeks of gestation by magnetic resonance imaging: Comparison with embryonic liver at Carnegie stage 23. Hepatol Res 43:639-647.

Hansen DV, Lui JH, Parker PRL, Kriegstein AR. 2010. Neurogenic radial glia in the outer subventricular zone of human neocortex. Nature 464:554-561.

Hirose A, Nakashima T, Yamada S, Uwabe C, Kose K, Takakuwa T. 2012. Embryonic liver morphology and morphometry by magnetic resonance microscopic imaging. Anat Rec (Hoboken) 295: 51-9.

Nishimura H, Takano K, Tanimura T, Yasuda M. 1968. Normal and abnormal development of human embryos: first report of the analysis of 1,213 intact embryos. Teratology 1:281-290.

Sakai T, Mikami A, Tomonaga M, Matsui M, Suzuki J, Hamada Y, Tanaka M, Miyabe-Nishiwaki T, Makishima H, Nakatsukasa M, Matsuzawa T. 2011. Differential prefrontal white matter development in chimpanzees and humans. Curr Biol 21:1397-1402.

Sawada K, Hikishima K, Murayama AY, Okano HJ, Sasaki E, Okano H. 2014. Fetal sulcation and gyrification in common marmosets (Callithrix jacchus) obtained by ex vivo magnetic resonance imaging. Neuroscience 257:158-174.

Sawada K, Fukunishi K, Kashima M, Saito S, Sakata-Haga H, Aoki I, Fukui Y. 2012. Fetal gyrification in cynomolgus monkeys: a concept of developmental stages of gyrification. Anat Rec (Hoboken) 295:1065-1074.

Sawada K, Sun XZ, Fukunishi K, Kashima M, Saito S, Sakata-Haga H, Sukamoto T, Aoki I, Fukui Y. 2010. Ontogenetic pattern of gyrification in fetuses of cynomolgus monkeys. Neuroscience 167:735-740.

This article is protected by copyright. All rights reserved. 
Shiota K. 1991. Development and intrauterine fate of normal and abnormal human conceptuses. Congenit Anom 31:67-80.

Toro R, Perron M, Pike B, Richer L, Veillette S, Pausova Z, Paus T. 2008. Brain size and folding of the human cerebral cortex. Cereb Cortex 18:2352-2357.

Van Duijn S, Nabuurs RJ, van Rooden S, Maat-Schieman ML, van Duinen SG, van Buchem MA, van der Weerd L, Natté R. 2011. MRI artifacts in human brain tissue after prolonged formalin storage. Magn Reson Med 65:1750-1758.

Wobrock T, Gruber O, Mclntosh AM, Kraft S, Klinghardt A, Scherk H, Reith W,

Schneider-Axmann T, Lawrie SM, Falkai P, Moorhead TW. 2010. Reduced prefrontal gyrification in obsessive-compulsive disorder. Eur Arch Psychiatry Clin Neurosci 260; 455-464.

Yamada S, Uwabe C, Fujii S, Shiota K. 2004. Phenotypic variability in human embryonic holoprosencephaly in the Kyoto Collection. Birth Defects Res A Clin Mol Teratol 70:495-508. Zilles K, Armstrong E, Schleicher A, Kretschmann HJ. 1988. The human pattern of gyrification in the cerebral cortex. Anat Embryol 179:173-179. 


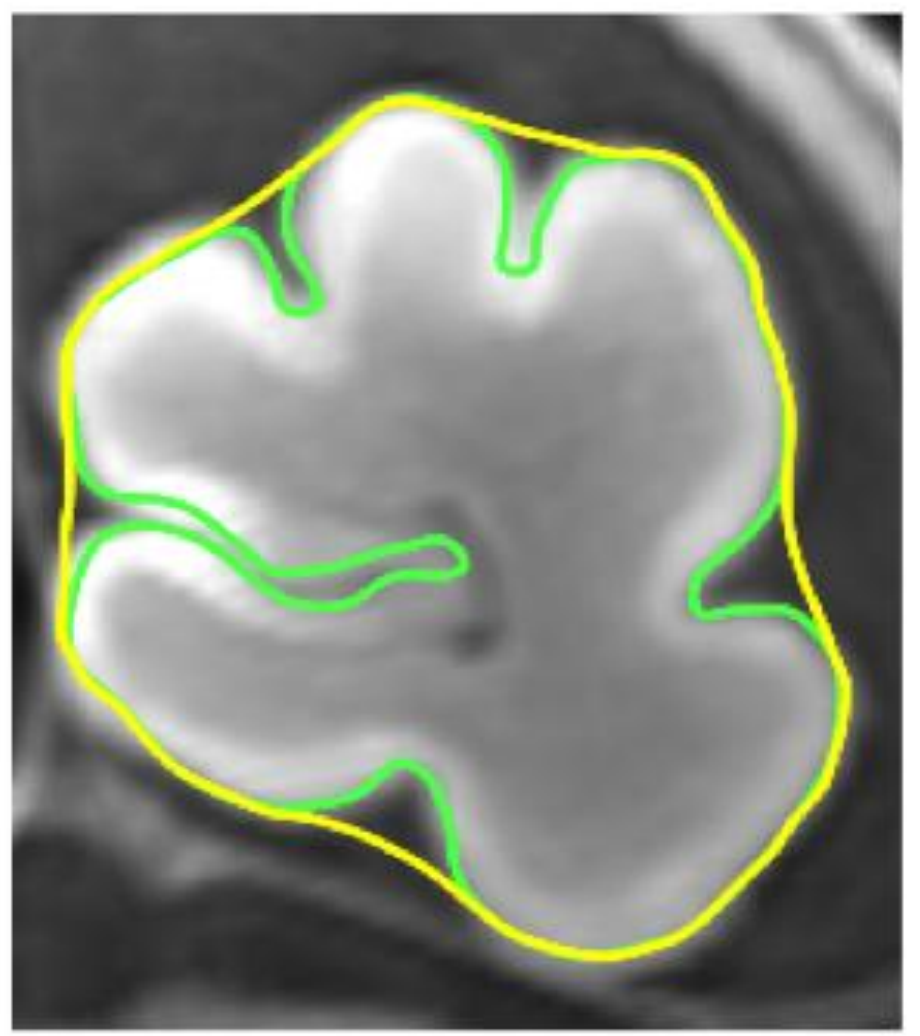

Fig. 1 Drawing of the outer (yellow line) and inner (green line) contour of a representative coronal MR slice of the cerebral hemisphere. The $\mathrm{Gl}$ is calculated from the ratio between the outer and inner contours.

This article is protected by copyright. All rights reserved. 


$$
\mathrm{GI}=1.08
$$

A
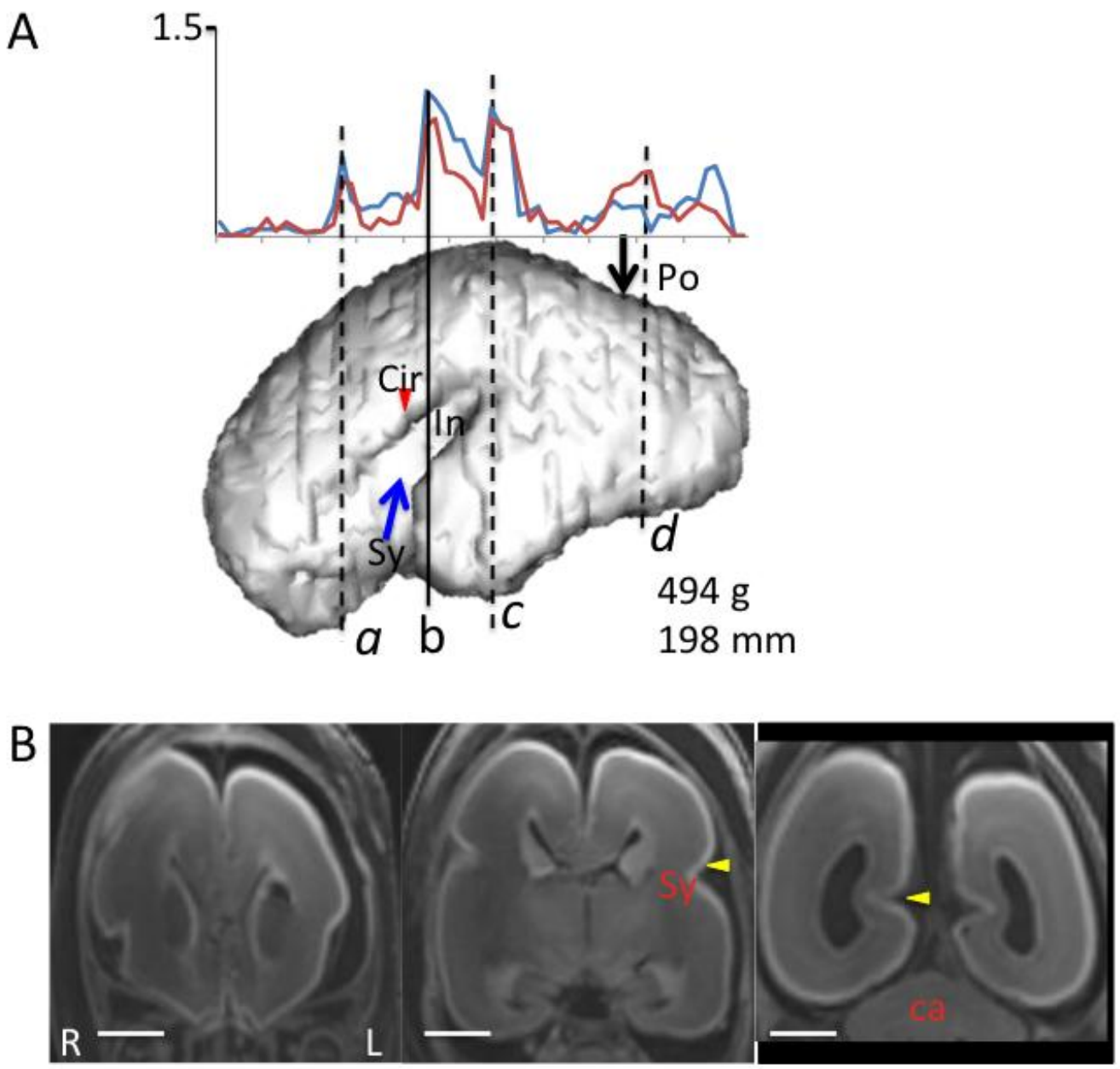

Fig. 2 Gyrification index (GI) of brain slices in a left lateral view of the brain (A) and representative coronal sections across the anterior-posterior axis of the forebrain (B) at gestational age (GA) 21 weeks.

The line graph above the brain shows the Gl of each slice below it (blue $=\mathrm{Gl}$ of left hemisphere; red $=\mathrm{Gl}$ of right hemisphere). Body weight, $\mathrm{CRL}$, and average $\mathrm{Gl}$ values are listed in the text to the bottom right of each brain image. The black dashed lines corresponding to the coronal sections ( $\mathrm{a}, \mathrm{c}$, and $\mathrm{d}$ in $\mathrm{B})$ are shown.

Ca; calcarine sulcus, Cir; circular sulcus, Po; posterooccipital sulcus, Sy; sylvian fissure 


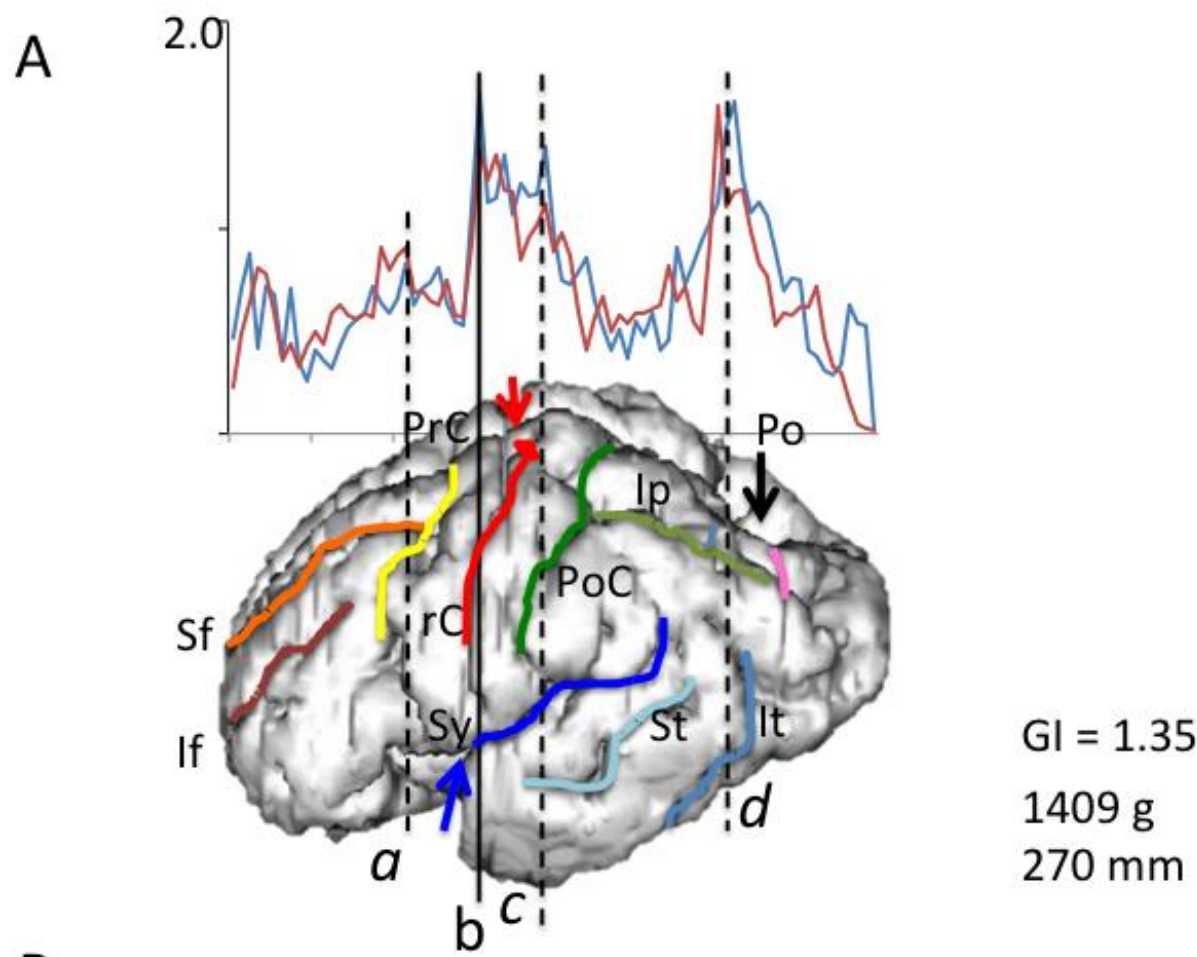

B

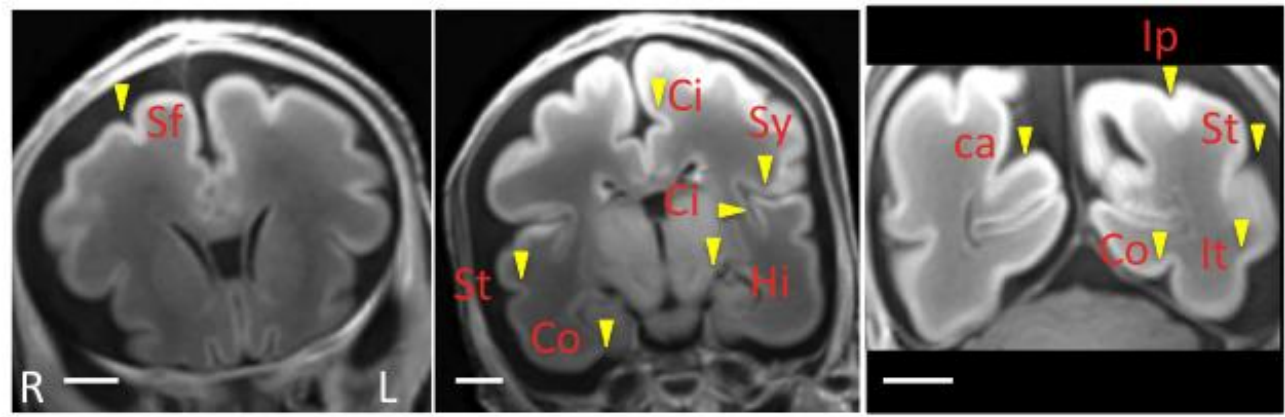

Fig. 3 Gyrification index (GI) of brain slices in a left lateral view of the brain (A) and representative coronal sections across the anterior-posterior axis of the forebrain (B) at gestational age (GA) 31 weeks.

The line graph above the brain shows the Gl of each slice below it (blue = Gl of left hemisphere; red $=\mathrm{Gl}$ of right hemisphere). Body weight, $\mathrm{CRL}$, and average $\mathrm{Gl}$ are listed in the text to the bottom right of each brain image. The black dashed lines correspond to the coronal sections (a, c, and d in B) are shown.

$\mathrm{Ca}$; calcarine sulcus, $\mathrm{Ci}$; cingulate sulcus, Cir; circular sulcus, Co; collateral sulcus, Hi; 
hippocampal sulcus, If: inferior frontal sulcus, Ip: intraparietal sulcus, It; inferior temporal sulcus, Po; posterooccipital sulcus, PoC: postcentral sulcus, PrC: precentral sulcus, rC: rolandic central sulcus, Sf: superior frontal sulcus, St: superior temporal sulcus, Sy: sylvian fissure 

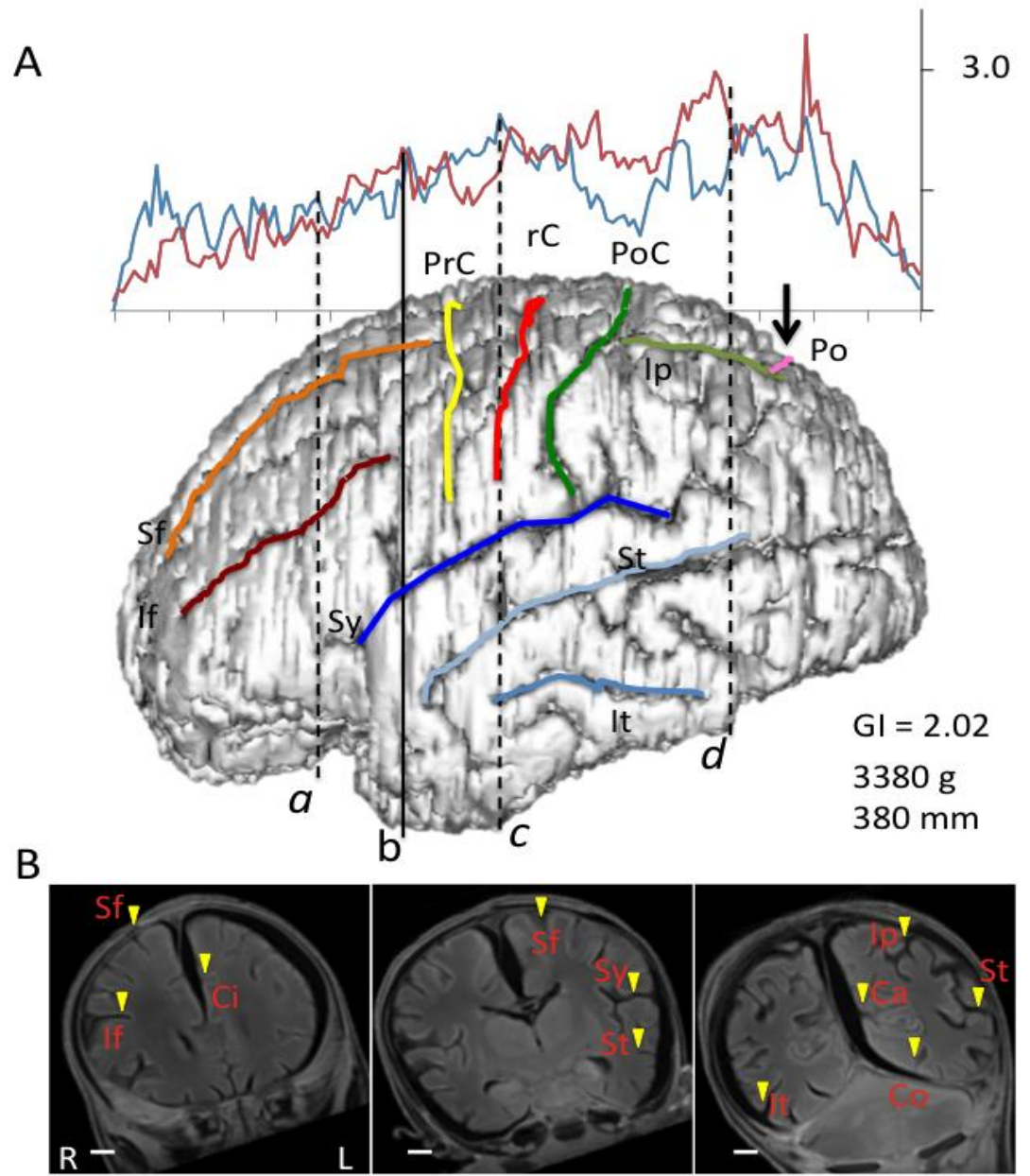

Fig. 4 Gyrification index (GI) of brain slices in a left lateral view of the brain (A) and representative coronal sections across the anterior-posterior axis of the forebrain (B) at gestational age (GA) 40 weeks.

The line graph above the brain shows the $\mathrm{Gl}$ of each slice below it (blue $=\mathrm{Gl}$ of left hemisphere; red $=\mathrm{Gl}$ of right hemisphere). Body weight, $\mathrm{CRL}$, and average $\mathrm{Gl}$ are listed in the text to the bottom right of each brain image. The black dashed lines correspond to the coronal sections ( $\mathrm{a}, \mathrm{c}$, and $\mathrm{d}$ in $\mathrm{B})$ are shown.

Ca; calcarine sulcus, Ci; cingulate sulcus, Co; collateral sulcus, If: inferior frontal sulcus, Ip: intraparietal sulcus, Po; posterooccipital sulcus, PoC: postcentral sulcus, PrC: precentral sulcus, rC: rolandic central sulcus, Sf: superior frontal sulcus, St: superior temporal sulcus, Sy: sylvian fissure 


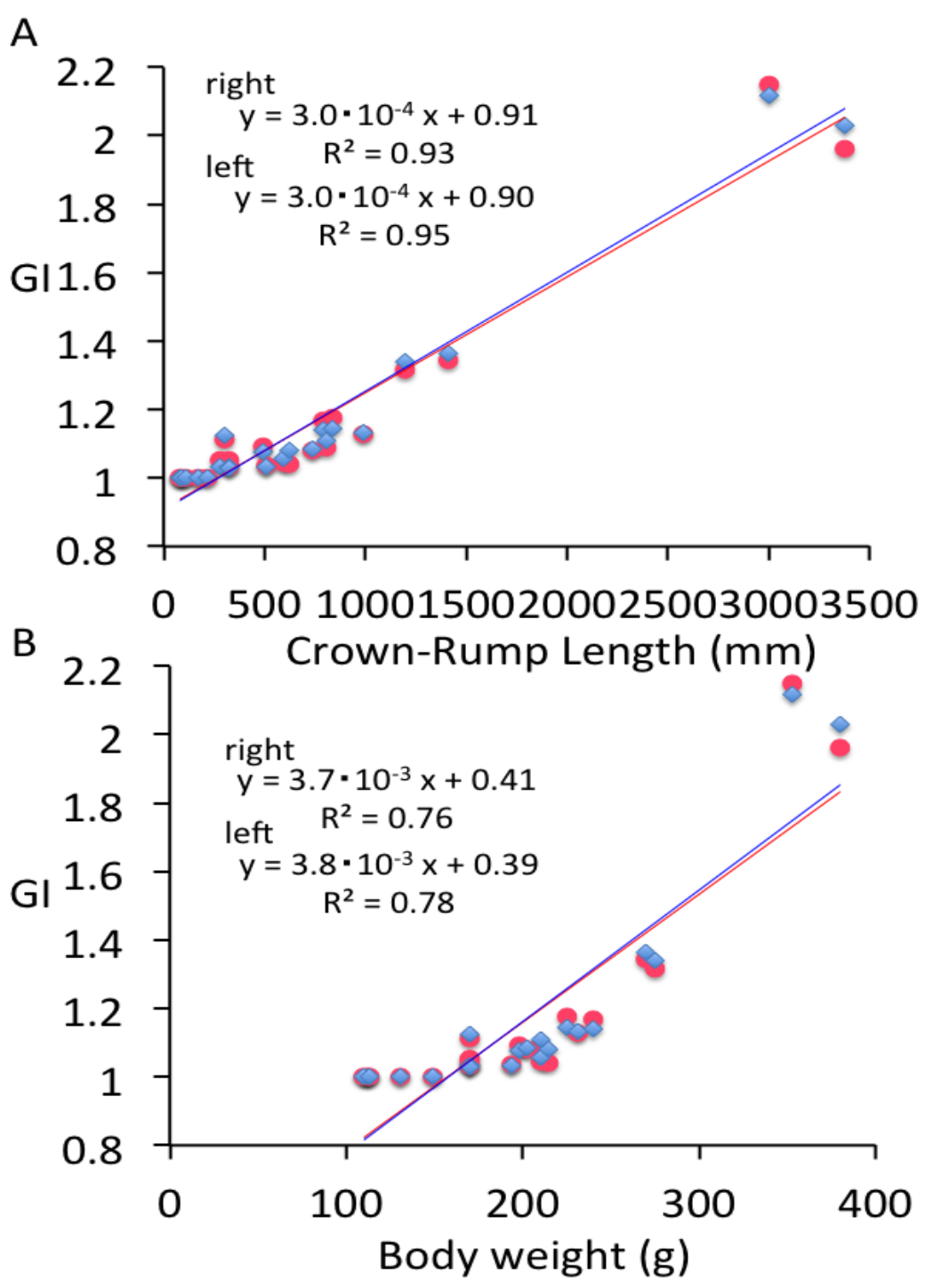

Fig. 5 Correlation of the crown-rump length $(A)$ and body weight $(B)$ with $\mathrm{Gl}$.

Plots of GI (Y axis) against crown-rump length (top) and body weight (bottom) on the $\mathrm{x}$ axis, demonstrating a significant correlation of GI with both variables. Note the $R^{2}$ values above the best fit lines. Blue; left hemisphere, Red; right hemisphere. 
A

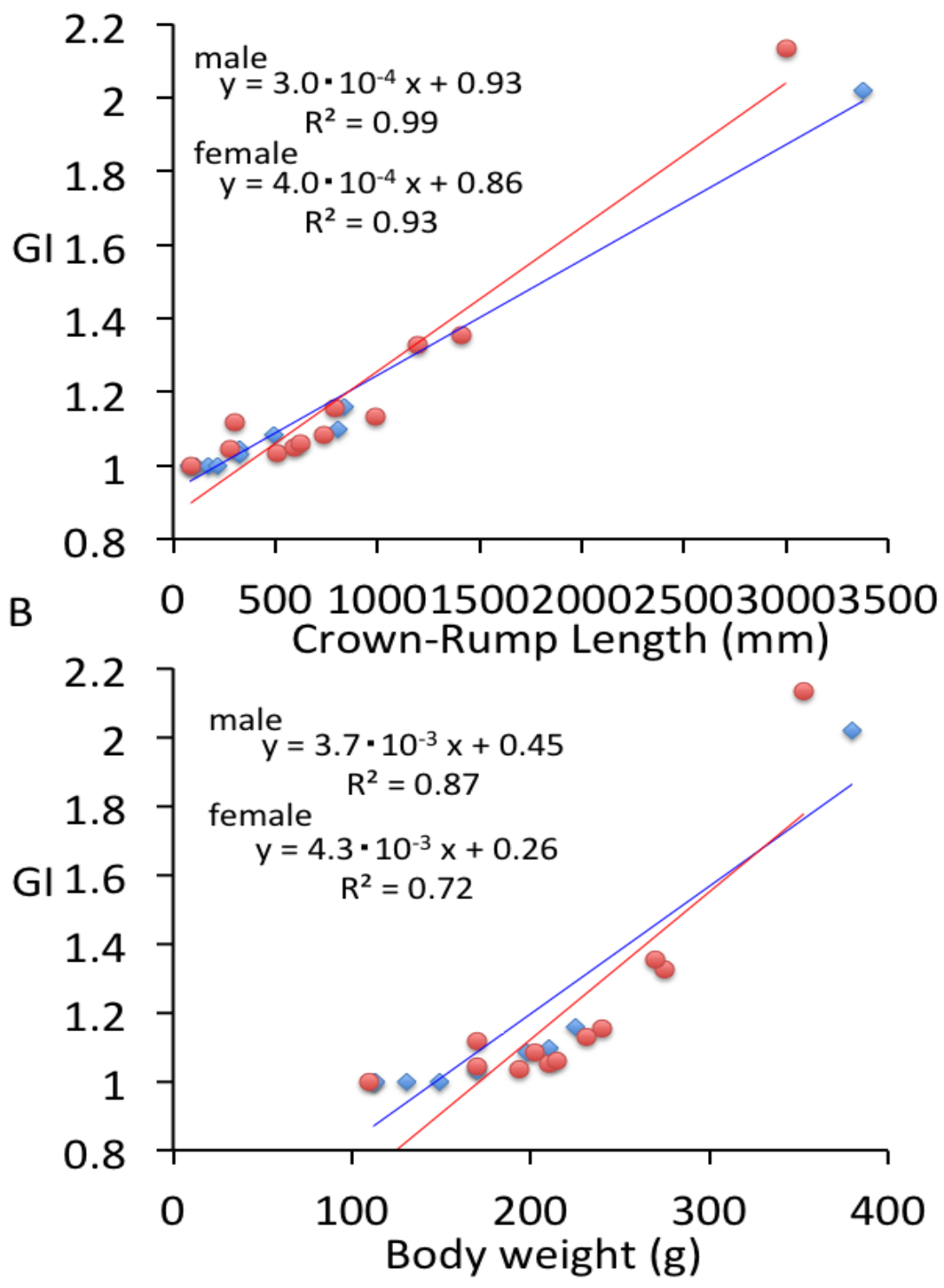

Fig. 6 Correlation of the crown-rump length $(A)$ and body weight $(B)$ with $\mathrm{Gl}$.

Plots of $\mathrm{Gl}$ (Y axis) against crown-rump length (top) and body weight (bottom) on the $\mathrm{x}$ axis, demonstrating a significant correlation of GI with both variables. Note the $\mathrm{R}^{2}$ values above the best fit lines. Blue; male, Red; female. 


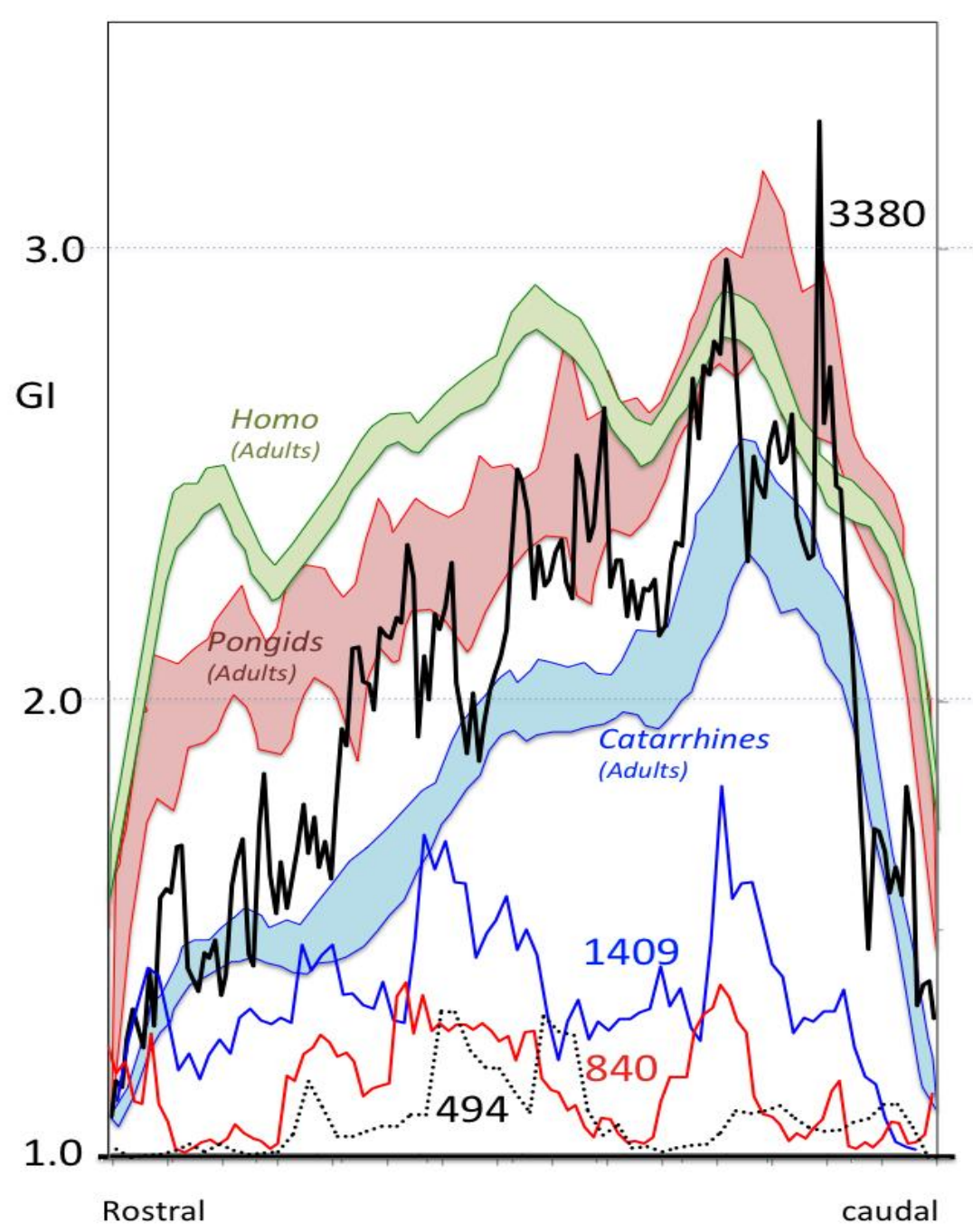

Fig. 7 Mean Gl varies along the rostro-caudal course through the left hemispheres of 4 different fetal brains.

Line graphs showing mean $\mathrm{Gl}$ (y axis) axis across the rostro-caudal cerebral course ( $\mathrm{x}$ axis). Solid lines indicate the fetal human samples. Numbers indicate the body weight of each sample (494 g, $840 \mathrm{~g}, 1409 \mathrm{~g}, 3380 \mathrm{~g}$ ). The shaded interval plots represent the curves of the $95 \%$ confidence interval of the adult human, pongid, and catarrhine brains shown in green, red, and blue, respectively (ref. Figures 7 and 8 in Zilles et al. 1988). 
Table 1 Summary of the samples used in the present study

\begin{tabular}{|c|c|c|c|c|c|c|c|c|}
\hline \multirow{2}{*}{$\begin{array}{l}\text { Run } \\
\text { No. }\end{array}$} & \multirow{2}{*}{ Sex } & \multirow{2}{*}{$\begin{array}{l}\text { Body } \\
\text { weight } \\
\text { (g) }\end{array}$} & \multirow{2}{*}{$\begin{array}{l}{ }^{1)} \mathrm{CRL} \\
(\mathrm{mm})\end{array}$} & \multirow{2}{*}{$\begin{array}{l}{ }^{2)} \mathrm{Age} \\
(\text { weeks) }\end{array}$} & \multirow{2}{*}{$\begin{array}{l}\text { Way of } \\
\text { Delivery }\end{array}$} & \multicolumn{3}{|c|}{ Gyrification Index } \\
\hline & & & & & & right & left & total \\
\hline 1872 & M & 81 & 112 & 17 & 4) IAS & 1 & 1 & 1 \\
\hline 2087 & $\mathrm{~F}$ & 86 & 110 & 15 & IAS & 1 & 1 & 1 \\
\hline 2090 & M & 112 & 113 & ${ }^{3)} \mathrm{ND}$ & IAS & 1 & 1 & 1 \\
\hline 2099 & M & 170 & 131 & 18 & IAS & 1 & 1 & 1 \\
\hline 2083 & M & 219 & 149 & ND & IAS & 1 & 1 & 1 \\
\hline 2091 & $\mathrm{~F}$ & 281 & 170 & ND & IAS & 1.05 & 1.03 & 1.04 \\
\hline 2097 & $\mathrm{~F}$ & 303 & 170 & ND & IAS & 1.11 & 1.12 & 1.12 \\
\hline 1873 & $M$ & 322 & 170 & ND & IAS & 1.05 & 1.03 & 1.04 \\
\hline 2081 & M & 324 & 170 & ND & IAS & 1.03 & 1.03 & 1.03 \\
\hline 2077 & M & 494 & 198 & 23 & IAS & 1.09 & 1.08 & 1.08 \\
\hline 2076 & $\mathrm{~F}$ & 505 & 194 & 24 & ${ }^{5)}$ IAM & 1.04 & 1.03 & 1.03 \\
\hline 2096 & $\mathrm{~F}$ & 594 & 210 & 23 & IAS & 1.04 & 1.06 & 1.05 \\
\hline 2095 & $F$ & 622 & 215 & 18 & IAS & 1.04 & 1.08 & 1.06 \\
\hline 1763 & $\mathrm{~F}$ & 740 & 202 & 19 & IAS & 1.08 & 1.09 & 1.08 \\
\hline 2079 & $\mathrm{~F}$ & 790 & 240 & ND & IAS & 1.17 & 1.14 & 1.15 \\
\hline 1882 & M & 810 & 210 & 21 & IAS & 1.09 & 1.11 & 1.1 \\
\hline 1764 & M & 840 & 225 & 27 & IAM & 1.18 & 1.14 & 1.16 \\
\hline 1760 & $F$ & 987 & 231 & 26 & IAS & 1.13 & 1.13 & 1.13 \\
\hline 1867 & $F$ & 1200 & 275 & 28 & IAM & 1.32 & 1.34 & 1.33 \\
\hline 2094 & $F$ & 1409 & 270 & 31 & ${ }^{6)} \mathrm{Hy}$ & 1.34 & 1.37 & 1.35 \\
\hline 1866 & $\mathrm{~F}$ & 3000 & 353 & 38 & ${ }^{7)} \mathrm{CS}$ & 2.15 & 2.12 & 2.13 \\
\hline 1868 & M & 3380 & 380 & 40 & CS & 1.96 & 2.03 & 2.02 \\
\hline
\end{tabular}

1) CRL, crown-ramp length;

2) Age, weeks of gestation defined from the last maternal menstrual period

3) ND, not described; 4) IAS; Induced abortion for socioeconomic reasons

5) IAM; Induced abortion for some medical or clinical reasons

6) Hysterectomy due to placenta previa

7) Cesarean section due to non-reassuring fetal status 